\title{
A study of the peripheral nerves in diabetic subjects during ischaemia
}

\author{
GUNNAR GREGERSEN
}

\begin{abstract}
From the Second Clinic of Internal Medicine and the Department of Neurology, Kommunehospitalet, Aarhus University School of Medicine, Aarhus, Denmark
\end{abstract}

The observance of pathological changes in the blood vessels of nerves from diabetics (Woltman and Wilder, 1929; Fagerberg, 1959) and the demonstration of progressive functional defects which parallel the duration of diabetes (Steiness, 1957; Fagerberg, Petersén, Steg, and Wilhelmsen, 1963; Gregersen, 1967, 1968a, b) have established and supported the theory that diabetic neuropathy is a manifestation of diabetic angiopathy just as, for example, diabetic nephropathy is.

Several investigators have, however, retained the view that the metabolic disturbance of diabetes also exerts a more direct effect on peripheral nerves. This latter view is supported by clinical observations of both older and more recent date to the effect that reflex and sensory abnormalities can change with changes in the metabolic state. In addition, some workers find no correlation between histological nerve degeneration and changes in the vasa nervorum in very old diabetics and in diabetics who have had the disease for many years.

Eliasson (1964) found a reduction in nerve conduction velocity in alloxan-diabetic and pancreatectomized rats. This reduction was not, under the stated experimental conditions, reversible with insulin therapy.

It has recently been demonstrated in humans (Gregersen, 1967, 1968a, b) that both sensory and motor nerve function is reduced early in the course of diabetes. It is unlikely that there is a significant abnormality of the vasa nervorum at this stage of the disease. In a group of young diabetics of the same age and duration of disease, the mean motor nerve velocity was lower in those in whom the metabolic state was poorly controlled than in those in whom it was well controlled.

The most convincing demonstration of the influence of the metabolic state on nerve function in diabetics has been made by Steiness (1961b). He showed that vibration sense during ischaemia is better retained in diabetics than in normal people. This paradoxical phenomenon was, in addition, reversible after careful normalization of the blood sugar.
Vibration sense cannot, however, be regarded as a basal sensory modality. It is rather a special way of simultaneously stimulating several different sense organs. The object of the present investigation has therefore been to determine if the abnormal nerve response which has been demonstrated for vibration sense in diabetics during ischaemia could also be demonstrated for the basal sensory modalities and for motor nerve function.

\section{METHODS}

Sixteen non-diabetics, eight men and eight women, and 24 randomly selected diabetics, 16 men and eight women, were studied. There were three medical students and 13 patients with minor disorders such as cephalalgia, lipothymia, and neurosis among the non-diabetics. The non-diabetics were from 15 to 32 years of age, the diabetics were from 13 to 39 years of age. After the first measurements, the metabolic status of eight of the diabetics was very strictly regulated for a period of several days so that there was no or only slight glucosuria, and the measurements were then repeated. Seven of these eight diabetics had not previously been treated and three had slight ketonuria. None of the patients was severely ketotic and all of them were ambulatory (Table I). Among the diabetics there were five (Nos. 8, $12,15,16$, and 23 in Table I) with clinical loss of sensibility or deep reflexes. Their mode of reaction during the tests was not different from that of the other diabetics in the group.

VIBRATION SENSE This was measured according to Steiness (1957) with a biothesiometer (Bio-Medical Instrument Company, Chagrin Falls, Ohio, U.S.A.). Vibratory perception threshold (VPT) was read on a voltmeter with a scale from 0 till 50 . The mean of two measurements done on the pulp of the great toe was used.

SENSE OF TOUCH This was estimated in two ways: (1) as the number of scores out of 20 possible obtained by touching the dorsum of the foot with von Frey's hair in a circle with a diameter of $6.5 \mathrm{~cm}$ (the hair was a nylon thread with a diameter of $0.3 \mathrm{~mm}$; the stimulus given was $23 \mathrm{~g} / \mathrm{sq} . \mathrm{mm}$ ); (2) by determining with a piece of cotton-wool the upper limit of the ascending hypaesthesia and anaesthesia produced by ischaemia. 
TABLE I

\begin{tabular}{|c|c|c|c|c|c|c|c|c|c|c|}
\hline \multicolumn{10}{|c|}{ DIABETIC SUBJECTS BEFORE AND AFTER INTENSE TREATMENT } & $\bar{q}$ \\
\hline $\begin{array}{l}\text { Subject } \\
\text { No. }\end{array}$ & $\begin{array}{l}\text { Age } \\
(y r)\end{array}$ & $\begin{array}{l}\text { Dur. of } \\
\text { Diabetes } \\
(y r) \\
\end{array}$ & $\begin{array}{l}\text { Fasting } \\
\text { Blood } \\
\text { Sugar } \\
(\mathrm{mg} \%)\end{array}$ & $\begin{array}{l}\text { Slight } \\
\text { Ketosis }\end{array}$ & $\begin{array}{l}\text { 24-hour } \\
\text { Urine } \\
\text { Sugar } \\
(\%)\end{array}$ & $\begin{array}{l}\text { Insulin } \\
\text { (i.u.) }\end{array}$ & $\begin{array}{l}\text { Fasting } \\
\text { Blood } \\
\text { Sugar } \\
(\mathrm{mg} \%)\end{array}$ & $\begin{array}{l}\text { 24-hour } \\
\text { Urine } \\
\text { Sugar } \\
(\%)\end{array}$ & $\begin{array}{l}\text { Insulin } \\
\text { (i.u.) }\end{array}$ & 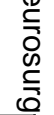 \\
\hline 1 & 18 & 4 & 129 & & 0.0 & 52 & & & & $\infty$ \\
\hline 2 & 19 & 8 & 274 & & 0.9 & 72 & & & & $\stackrel{\infty}{\sim}$ \\
\hline 3 & 25 & 2 & 238 & & $4 \cdot 2$ & 20 & & & & ఏ) \\
\hline 4 & 32 & $3 / 4$ & 41 & & $1 \cdot 1$ & 44 & & & & ㅁ. \\
\hline 5 & 16 & 2 & 145 & & 1.2 & 36 & & & & 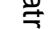 \\
\hline 6 & 20 & 12 & 234 & & $3 \cdot 2$ & 44 & & & & হ \\
\hline 7 & 15 & 2 & 298 & & 1.9 & 68 & & & & $\Rightarrow$ \\
\hline 8 & 31 & 24 & 337 & & 2.5 & 44 & & & & $\bar{\omega}$ \\
\hline 9 & 21 & 9 & 109 & & 0.6 & 52 & & & & (u) \\
\hline 10 & 22 & $1 / 4$ & 140 & & 0.0 & 0 & & & & 믈 \\
\hline 11 & 25 & 0 & 227 & & $5 \cdot 4$ & 0 & 66 & 0.0 & 12 & $\bar{z}$ \\
\hline 12 & 36 & 19 & 108 & & 1.1 & 44 & & & & $=$ \\
\hline 13 & 39 & 19 & 105 & & $1 \cdot 3$ & 56 & & & & \\
\hline 14 & 13 & 1 & 230 & + & $7 \cdot 2$ & 0 & 77 & 0.0 & 36 & 2 \\
\hline 15 & 30 & 14 & 203 & & 0.2 & 36 & & & & \\
\hline 16 & 18 & 10 & 164 & + & $5 \cdot 2$ & 32 & & & & ע \\
\hline 17 & 18 & 14 & 181 & + & $5 \cdot 2$ & 40 & 66 & & 56 & ـ \\
\hline 18 & 20 & 4 & 78 & & 1.0 & 84 & & & & \\
\hline 19 & 32 & 0 & 191 & & $4 \cdot 2$ & 0 & 142 & 0.6 & 76 & $\Delta$ \\
\hline 20 & 38 & 0 & 226 & + & $6 \cdot \overline{6}$ & 0 & 91 & 0.0 & 24 & \\
\hline 21 & 19 & 0 & 240 & & 6.5 & 0 & 80 & $0 \cdot 3$ & 84 & W \\
\hline 22 & 23 & 0 & 260 & & $6 \cdot 3$ & 0 & 117 & 0.0 & 20 & \\
\hline 23 & 26 & 7 & 66 & & 0.0 & 60 & & & & \\
\hline 24 & 21 & $3 / 4$ & 253 & & 6.7 & 0 & 73 & 0.1 & 60 & \\
\hline
\end{tabular}

SENSE OF PAIN This was also estimated in two ways: (1) by determining with pinprick the upper limit of the ascending hypalgesia and analgesia produced by ischaemia; (2) as heat-induced pain in connection with estimation of the sense of temperature.

SENSE OF TEMPERATURE This was estimated with a variable heat generator consisting of a $25 \mathrm{~W}, 12 \mathrm{~V}$ electric bulb placed at the bottom of a $13-\mathrm{cm}$ long brass cylinder with an internal diameter of $5.3 \mathrm{~cm}$. The inner surface of the cylinder was highly polished. The free end was placed at a constant distance of $3 \mathrm{~mm}$ from the dorsum of the foot with the use of a collar made of non-heat-conducting material. After the device was positioned, the heat generator was smoothly and evenly brought up to maximum effect in the course of $30 \mathrm{sec}$. The time interval in seconds to the first perception of warmth, and then of pain, was noted.

MOTOR NERVE CONDUCTION VELOCITY This was measured in the peroneal nerve as described previously (Gregersen, 1967a), except that surface stimulation electrodes were not used. Instead, two non-insulated needle electrodes placed subcutaneously $2.5 \mathrm{~cm}$ apart over the nerve at the ankle and head of the fibula were employed, and thus the same loci were stimulated throughout the experiment.

Immediately after completion of the first measurements of nerve function, blood circulation to the lower extremities was arrested by placing a $13-\mathrm{cm}$ wide pneumatic cuff with a pressure of $200-250 \mathrm{~mm} \mathrm{Hg}$ around the thigh. The lower border of the cuff was placed about $10 \mathrm{~cm}$ above the patella. Measurements were carried out every $5 \mathrm{~min}$ during ischaemia for $30 \mathrm{~min}$ and the cuff removed.
In the following illustrations, the upper graphs stow an average of all individuals tested, while the lower graphs show the same diabetics before and after he achievement of good metabolic status.

\section{RESULTS}

It was not possible to demonstrate any differe in the course of nerve function between men women in the ischaemia experiments, nor was there any difference in the type of reaction in diabetic with various durations of the disease. Therefore, nథ attention has been paid in the following to sex o duration of disease.

BIOTHESIOMETRY This was carried out in all the in $\overrightarrow{\overrightarrow{0}}$ dividuals studied. The results are shown in Figure $1^{3}$ In non-diabetics, vibratory perception threshold was increased to non-measurable values in the course of the first 20 min of ischaemia in severa subjects and in all of them before $30 \mathrm{~min}$ haक़ elapsed. Conversely, in the diabetics the VPT remained in the measurable range during the whole experiment; the average increase was modest and the standard deviation was small.

In the eight diabetics in whom the experiment was repeated after some days of careful normalization of the blood sugar, the course of the curve was markedly changed in the direction of normal.

MOTOR NERVE CONDUCTION VELOCITY This waSO measured in 13 non-diabetics and 17 diabetics and 

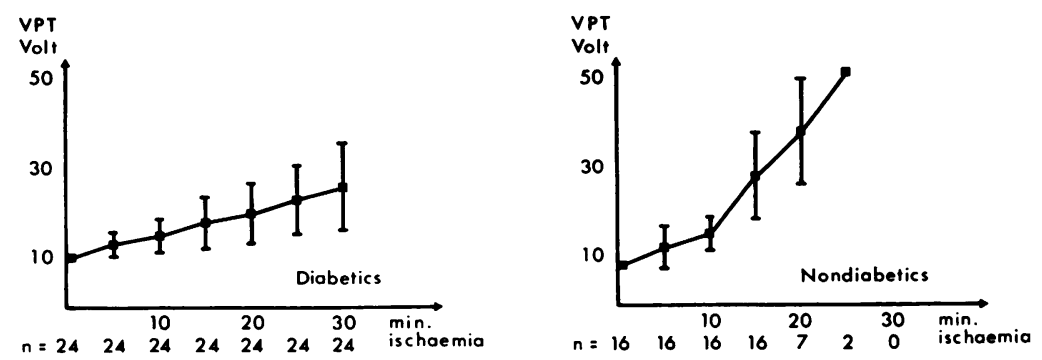

FIG. 1. Average increase in vibratory perception threshold at the great toe during arrested blood flow to the lower limb.
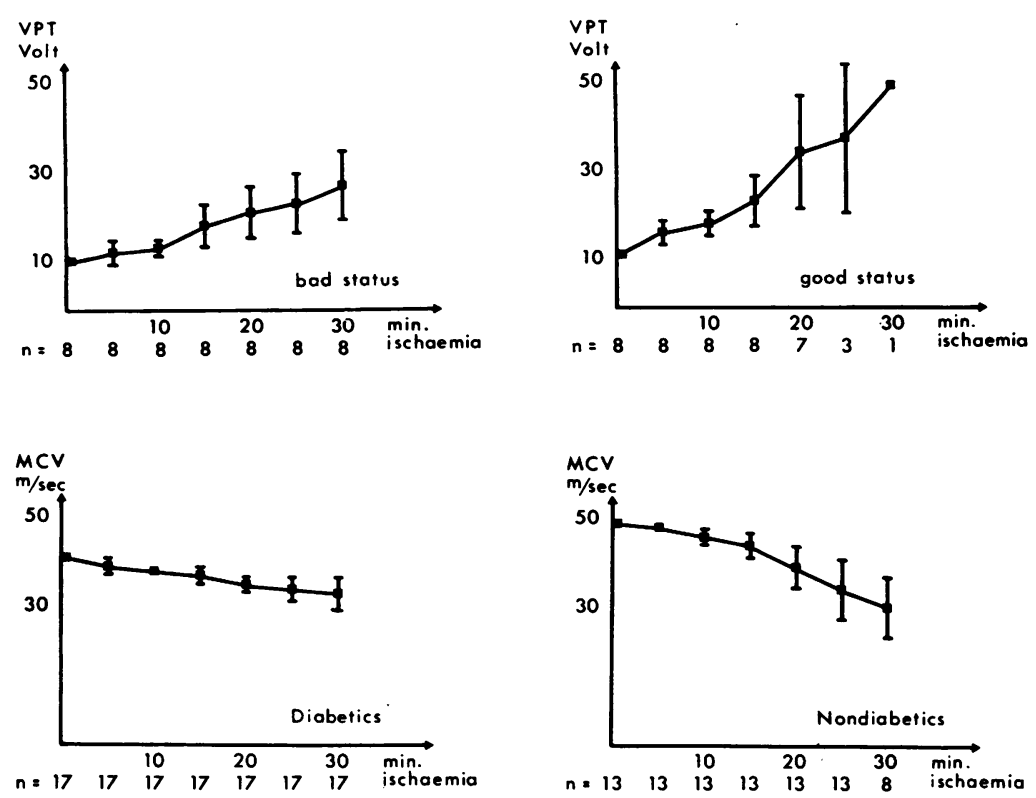

FIG. 2. Average decline in motor conduction velocity in the peroneal nerve during arrested blood flow to the lower limb.
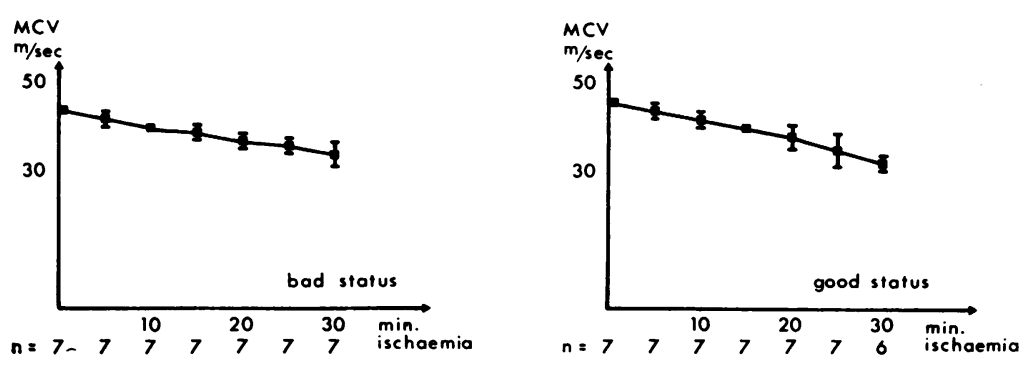

the results are given in Figure 2. Muscle potentials produced in the extensor digiti brevis muscle were so small in five of the normal individuals after 30 min of ischaemia that it was impossible to measure MCV. The same was true in one of the seven patients whose diabetic status was optimally regulated.

The average fall in MCV during ischaemia in the non-diabetics was significantly larger than in the diabetics $(19 \pm 7.0$ as against $8 \pm 3.5 \mathrm{~m} / \mathrm{sec}$, $P<0.001)$. The fall in the well-regulated diabetics was also larger than in the same diabetics during poor regulation $(14 \pm 2 \cdot 4$, as against $10 \pm 2 \cdot 6$ $\mathrm{m} / \mathrm{sec}, P<0.02)$.

SENSE OF TOUCH During ischaemia this was estimated with a von Frey hair (Fig. 3) and by following the 

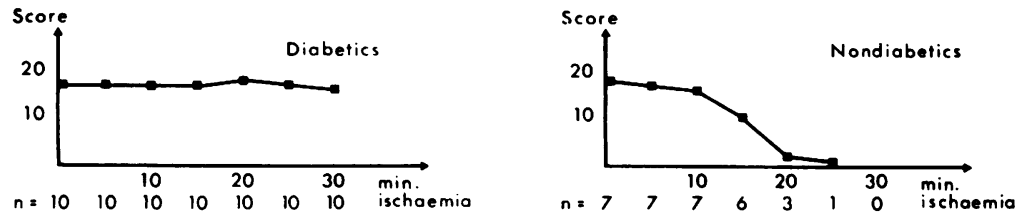

FIG. 3. Average score from 20 touches with von Frey's hair on the foot during arrested blood flow to the
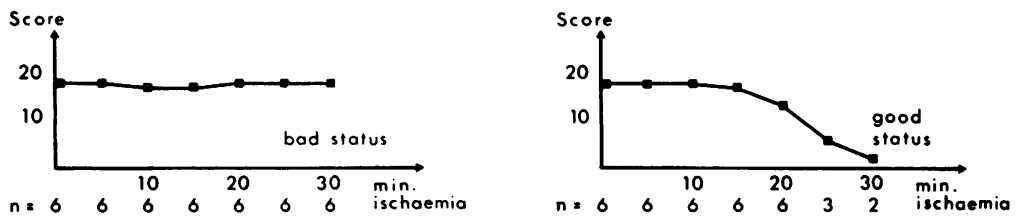
lower limb.
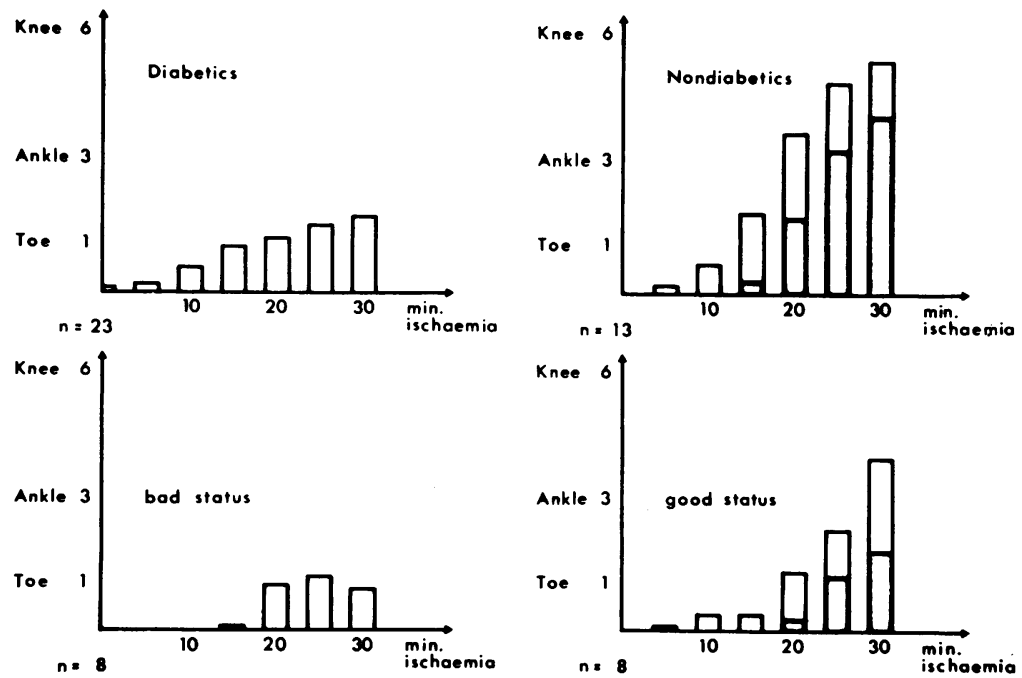

FIG. 4. Average upper limit of hypaesthetic area of the $\bar{O}$ lower limb during arrested $\vec{v}$ blood flow. Area outlined $\mathrm{S}_{\mathrm{y}}$ darker rule signifies anaesthesia.

upper border for hypaesthesia and anaesthesia. The limit of the border was given an arbitrary value starting with 1 at the base of the great toe and increasing to 6 at the knee and to 7 at the lower edge of the cuff about the thigh (Fig. 4).

It can be seen that the simple test using von Frey's hair gave a very distinct separation both between a random population of diabetics and non-diabetics and between diabetics in good and in poor regulation. The same holds true when the speed of the scending hy paesthesia produced by ischaemia is compared in the two groups. It should be noted that in diabetics it was possible to produce total anaesthesia only after rigorous control of the diabetes.
SENSE OF PAIN AND TEMPERATURE As with the sense of touch, the upper border of hypalgesia and analgesia for pinprick was followed (Fig. 5), and almost the same values were obtained. Pain sensitivity estimated, $\overline{ }$ using heat in connection with measurement of the sense of temperature, is also illustrated (Fig. 6) It can be seen that both pain and heat perception? measured as in this study remain unchanged during ischaemia. The course is the same in diabetics and in normal people, and in diabetics no change is seen after regulation of the metabolic status.

\section{DISCUSSION}

The present study has confirmed the demonstrationcw 

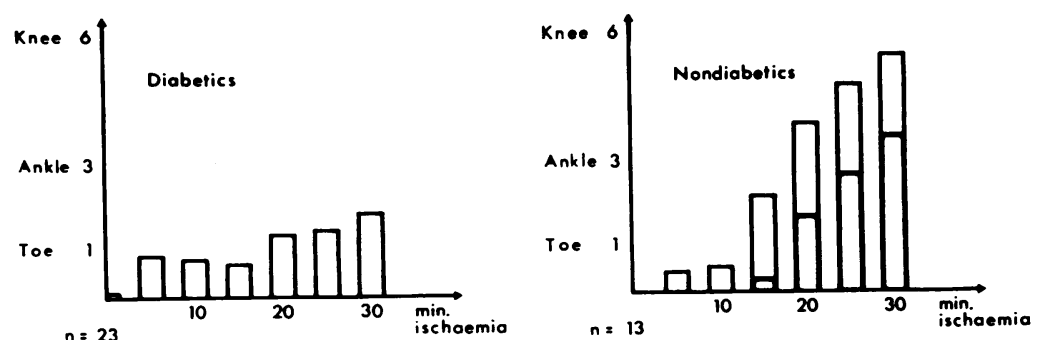

FIG. 5. Average upper limit of hypalgesic area of the lower limb during arrested blood flow. Area outlined by darker rule signifies analgesia.
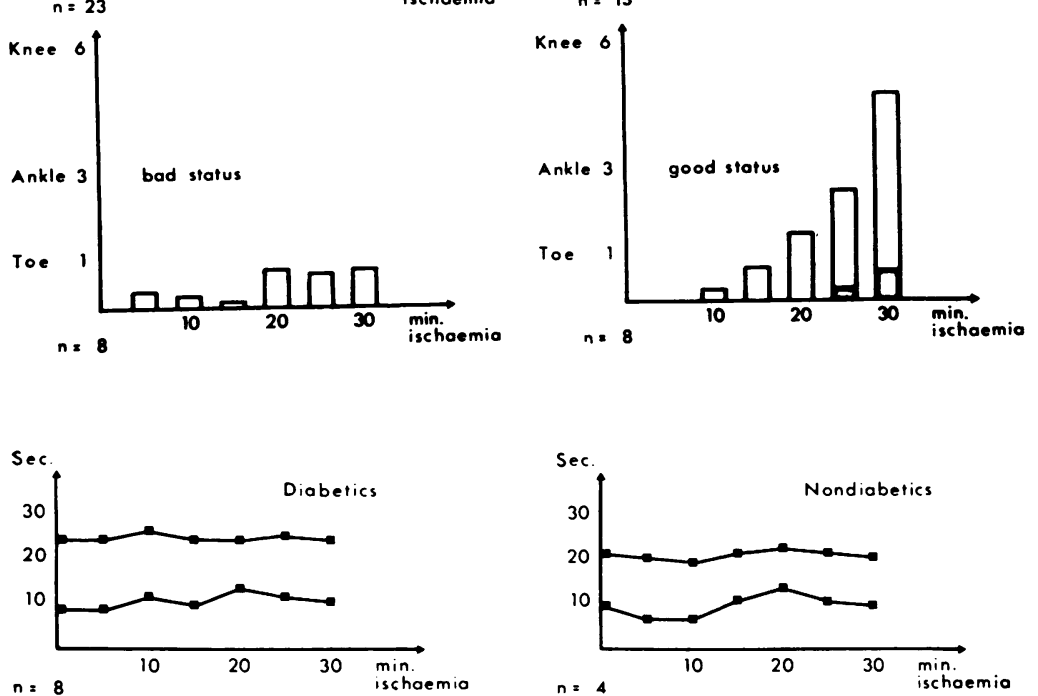

FIG. 6. Average latency for perception of warmth (lower curves) and pain (upper curves) by exposure of the foot to heat during arrested
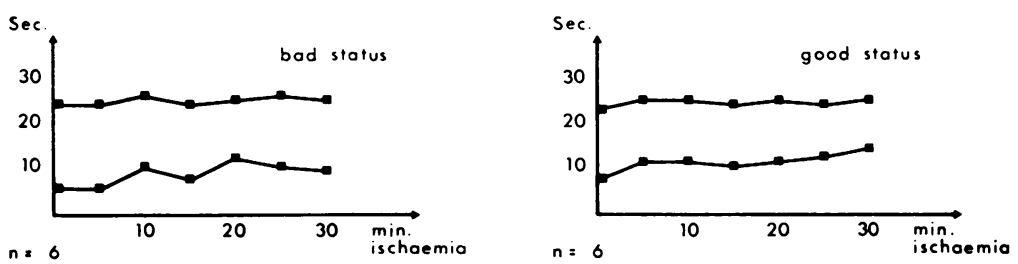
blood flow.

by Steiness that vibration sense is better preserved during ischaemia in diabetics than in normals. A phenomenon which is reversible if the diabetic metabolic abnormality be strictly regulated.

Castaigne, Cathala, Dry, and Mastropaolo (1966) have shown that nerve potentials fall off more rapidly in normal people than in diabetics during ischaemia. On the other hand, it was not possible for them to demonstrate any difference in the muscular response. This could perhaps be due to the fact that they stimulated only the distal end of the nerve where excitability is preserved longest during anoxia (Groat and Koenig, 1946).

The present experiments have shown that the peculiar resistence to ischaemia seen in diabetics applies not only to vibration sense but also to other sensory modalities, such as the sense of touch and pain as well as to motor nerve conduction.

This abnormal preservation of nerve function during ischaemia has up to the present been demonstrated only in diabetics. It has not been possible to reproduce this condition in normal individuals by administration of glucose or by the production of steroid or hunger diabetes (Steiness, 1961a). Just the opposite situation has been found with nerve lesions due to other causes - that is, a more rapid decrease in nerve function during ischaemia than in normal people (Gilliatt and Wilson, 1954; Fullerton, 1963).

This behaviour of nerve function during ischaemia 
is the most direct evidence now available for a metabolic effect on the peripheral nerves in diabetes.

A possible explanation for the phenomenon can perhaps be found in Shanes's (1951) demonstration of the antagonistic effect of glucose on nerve potential decrease and potassium loss in the peripheral frog nerve during anoxia. Shanes, however, used only glucose concentrations of $10 \mathrm{mM}$ or more, and his results do not explain the reason for the pronounced resistance of the unmyelinated, thermo-sensitive fibres to anoxia, nor does this work give an immediate explanation for the progressive reduction in nerve function that parallels the duration of diabetes, which rather suggests an association with the vascular abnormality of diabetes.

Unmyelinated fibres are the fibres most resistant to anoxia. A functional or morphological defect of the myelin sheaths could therefore explain not only the general reduction in function but also the abnormal reaction during ischaemia in diabetics. Histological changes in myelin sheaths have been described in diabetics by Thomas and Lascelles $(1965,1966)$ among others, but no study has yet been published on this subject in newly discovered diabetes in juvenile diabetics. Bischoff (1967) has reported that it is possible to demonstrate electronmicroscopic changes in diabetic animals a few weeks after administration of alloxan.

A third conceivable metabolic basis for changes in nerve function is the abnormality of the sorbitol pathway demonstrated by Stewart, Sherman, and Anthony (1966) and Gabbay, Merola, and Field (1966) in nerve tissue from alloxan diabetic rats. The sorbitol pathway in human diabetics has up to now been demonstrated only in kidney tissue (Gabbay and Field, 1966) and whether this metabolic abnormality could play a role in the function of the peripheral nerve fibres is unknown.

Decrease in nerve function cannot be explained on the basis of differences in rate of temperature fall in the legs during ischaemia in diabetics and non-diabetics. In both groups the fall was about $2{ }^{\circ} \mathrm{C} / 30 \mathrm{~min}$ in the anterior tibial muscle.

While there seems to be general agreement that the various sensory modalities are transmitted in well-defined tracts in the spinal cord, it is still not clear how cutaneous perception takes place and what connections the individual components in the peripheral nerves have with it. The theory of specific end-organs has been attacked by investigators who feel that the various sensory modalities should rather be thought of as different impulse patterns transmitted from identical end-organs. It has recently been shown that central mechanisms play a large and previously unnoticed role in the inter- action between the thickly and the thinly myelinate fibres in the peripheral nerves (Melzak and Walk 1965).

The sense of pain has in particular been mucs studied and debated; even the definition of pain if unclear. The skin can be acted upon in severat different ways to produce an unpleasant sensations and even though it is possible to separate these various stimuli from each other, they are still a felt as pain. Several investigators have shown tha $\vec{x}$ the sense of pain is transmitted through both and $\mathrm{C}$ fibres in the peripheral sensory nerves.

Two of the methods most often used in the study of pain perception have been pinprick and heat. Thes two sensory qualities have been shown in the presenf study to be fundamentally different. The pain o\$ pinprick disappears during ischaemia in non diabetics, while heat-induced pain persists. It thusseems reasonable to assume that the former is transmitted through thickly myelinated fibres, while the latter is transmitted through unmyelinate fibres.

\section{SUMMARY}

The present study has shown that not only vibration sense but also the senses of touch and pain, toget with motor nerve conduction velocity, are retaiped significantly better in diabetics than in normap individuals during ischaemia. On the other haod:the sense of heat and heat-induced pain were retained equally well in the two groups.

Just as with vibration sense, the other neive functions clearly change toward normal upoip careful regulation of diabetes.

In normal individuals the dissociation between analgesia for pinprick and persistence of heat $\frac{0}{\circ}$ induced pain during ischaemia provides new evidence that these two sensory modalities ar $\vec{E}$ transmitted through two different types of nerve fibres.

\section{REFERENCES}

Bischoff, A. (1967). Electronmicroscopic studies of peripheral nervep in alloxan diabetic hamsters. Prelim. rep., Diabetes Symposium? Zürich. To be published.

Castaigne, P., Cathala, H. P., Dry, J., and Mastropaolo, C. (1966)? Les résponses des nerfs et des muscles à des stimulationş électriques au cours d'une épreuve de garrot ischémique chez l'homme normal et chez le diabétique. Rev. neurol., 115, 61-66.

Eliasson, S. G. (1964). Nerve conduction changes in experimenta diabetes. $J$. clin. Invest., 43, 2353-2358.

Fagerberg, S. E. (1959). Diabetic neuropathy. A clinical and histoㅡ. logical study on the significance of vascular affections. Acta med. scand., 164, suppl. 345.

, Petersén, I., Steg, G., and Wilhelmsen, L. (1963). Motớ disturbances in diabetes mellitus. A clinical study using electromyography and nerve conduction velocity determination Ibid., 174, 711-716. 
Fullerton, P. M. (1963). The effect of ischaemia on nerve conduction in the carpal tunnel syndrome. J. Neurol. Neurosurg. Psychiat., 26, 385-397.

Gabbay, K. H., and Field, R. A. (1966). Accumulation of glucose, sorbitol and fructose in diabetic kidney. Diabetes, 15, 517.

--, Merola, L. O., and Field, R. A. (1966). Sorbitol pathway: Presence in nerve and cord with substrate accumulation in diabetes. Science, 151, 209-210.

Gilliatt, R. W., and Wilson, T. G. (1954). Ischaemic sensory loss in patients with peripheral nerve lesions. J. Neurol. Neurosurg. Psychiat., 17, 104-114.

Gregersen, G. (1967). Diabetic neuropathy: Influence of age, sex, metabolic control and duration of diabetes on motor conduction velocity. Neurology (Minneap.), 17, 972-980.

(1968a). Latency time, maximal amplitude and electromyographic pattern in diabetic patients. Acta med. scand., in press.

(1968b). Vibratory perception threshold and motor conduction velocity in diabetics and non-diabetics. Ibid., in press.

Groat, R. A., and Koenig, H. (1946). Centrifugal deterioration of asphyxiated peripheral nerve. J. Neurophysiol., 9, 275-284.

Melzak, R., and Wall, P. D. (1965). Pain mechanisms. A new theory. Science, 150, 971-979.
Shanes, A. M. (1951). Factors in nerve functioning. Fed. Proc., 10, 611-621.

Steiness, I. (1957). Vibratory perception in diabetics. Acta med. scand., 158, 327-335.

- (1961a). Vibratory perception in non-diabetic subjects during ischaemia, with special reference to the conditions in hyperglycaemia, after carbohydrate starvation and after cortisone administration. Ibid., 169, 17-26.

- (1961b). Influence of diabetic status on vibratory perception during ischaemia. Ibid., 170, 319-338.

Stewart, M. A., Sherman, W. R., and Anthony, S. (1966). Free sugars in alloxan diabetic rat nerve. Biochem. biophys. Res. Commun. 22, 488-491.

Thomas, P. K., and Lascelles, R. G. (1965). Schwann-cell abnormalities in diabetic neuropathy. Lancet, 1, 1355-1357.

(1966). The pathology of diabetic neuropathy. Quart. J. Med., 35, 489-509.

Woltman, H. W., and Wilder, R. M. (1929). Diabetes mellitus. Pathological changes in the spinal cord and peripheral nerves. Arch. intern. Med., 44, 576-603. 